\title{
AVALIAÇÃO DOS PERFIS BIOQUÍMICOS HEPÁTICO E RENAL EM CERDOCYON THOUS (CACHORRO DO MATO) SORORREAGENTES A LEPTOSPIRA SPP. NO TERRITÓRIO BRASILEIRO
}

\author{
(BIOCHEMICAL PROFILES EVALUATION IN LIVER AND KIDNEY OF CERDOCYON
} THOUS (CRAB EATING DOG) SEROPOSITIVE TO LEPTOSPIRA SPP. IN BRAZILIAN

TERRITORY)

\section{T. R. SILVA ${ }^{1 *}$, A. F. S. NOGUEIRA ${ }^{2}$, A. E. SANTANA ${ }^{3}$}

A leptospirose é uma zoonose que acomete animais domésticos, silvestres e o homem, afeta múltiplos órgãos e causa grave disfunção renal e hepática. O objetivo deste estudo foi avaliar os perfis bioquímicos hepático e renal de Cerdocyon thous (Cachorro do mato) de vida livre sororreagentes a sorovariedades de Leptospira spp. Foram colhidas amostras de sangue de 16 indivíduos de vida livre, de diferentes regiões no Brasil, das quais as amostras soropositivas foram destinadas à realização das análises bioquímicas de aspartato amino-transferase (AST), alanino amino-transferase (ALT), gamaglutamil transferase (GGT), ureia (UV), creatinina e albumina. Considerando os parâmetros propostos por Santos (1999), os valores médios de ALT (59,32 U/L) e AST (79,03 U/L) apresentaram-se elevados. O aumento de ALT no soro indica lesão hepática de natureza inflamatória, tóxica ou degenerativa, sendo que os níveis de sua elevação estão na dependência do grau e duração da lesão, obtendo-se concentrações maiores nos casos agudos (SANTOS, 1999). As concentrações séricas médias de albumina encontraram-se diminuídas $(1,82 \mathrm{~g} / \mathrm{dL})$. Níveis de albumina podem apresentar-se reduzidos pela produção diminuída, em casos de insuficiência hepática crônica ou por perda aumentada quando há glomerulonefrite (SANTOS, 1999). Um animal apresentou alteração na concentração sérica de ureia (138 mg/dL) e outro em GGT (122,4 U/L). De acordo com Wohl (1996), o aumento das enzimas hepáticas, da ureia e creatinina, podem ser devidos aos distúrbios hepático e renal. São necessários mais estudos sobre esta doença nos animais selvagens, contribuindo assim com projetos de conservação, manejo, prevenção e controle desta zoonose. Ademais, observou-se na literatura que os dados de parâmetros bioquímicos séricos são escassos ou ausentes para espécies selvagens. 